\title{
Features of mercury migration in natural objects of technogenically polluted areas
}

\author{
Marina Kubareva ${ }^{1}$, Elena Denisova ${ }^{1 *}$, Anatoly Soloviev ${ }^{2}$, and Vadim Smirnov ${ }^{1}$ \\ ${ }^{1}$ Omsk State Technical University, 644050 Omsk, Russian Federation \\ ${ }^{2}$ The Siberian State Automobile and Highway University, 644050 Omsk, Russian Federation
}

\begin{abstract}
The article discusses own studies' materials of anthropogenic mercury migration in the "soil- plant - surface water- water body bottom sediments" system on the example of technogenically mercury-polluted territory of the northern industrial zone of Pavlodar city in Kazakhstan. The mercury distribution processes in soil at a depth of up to two meters, in water and bottom sediments of the Irtysh River, as well as in "Pamyat' Azieva" soft spring wheat variety grown on soils with maximum pollution level were studied. It was discovered that the mercury migration degree to groundwater and plant objects depends on the soil type: so, it is minimal in chernozem soil. It was revealed that the mercury amount in the soil is in a positive correlation with its mineralization degree, filtration level, as well as the presence of chloride ions. The article also discusses the research results on the complex and diverse influence of predominant ions in soil, as well as their combinations on the content and distribution of mercury.
\end{abstract}

\section{Introduction}

Mercury is known to be the most dangerous toxicant due to its ability to migrate in sustainable state from atmospheric air to soil cover, vegetation, water bodies and animal organisms [1,2]. If mercury is coated with a thick silt layer in bottom sediments, its toxicity decreases, but this process is time-consuming. Several works confirmed low mercury mobility in soils at contaminated sites [3].

The industrial zone of Pavlodar city was chosen as the territory of the study; for a long time, it has been polluted because of the Pavlodar chemical plant operation, which performs electrolytic production of chlorine and caustic soda using mercury. According to expert estimates, the loss of metallic mercury during the operation of the enterprise amounted to 1,089 tons.

The processes of mercury migration in soils, plants, as well as with groundwater to water bodies were studied as the most important in terms of environmental safety and human health [2]. The relevance of the study is confirmed by many works devoted to the study of mercury accumulation by various agricultural plants (spinach $[2]$, rice $[4,5,6]$, ginger [7]) or forest leaf litter [8] and the study of ways to prevent this process. Nevertheless, there were no comprehensive studies on mercury migration and distribution

* Corresponding author: denisova_100@mail.ru 
in soils, bottom sediments and plants, determination of soil characteristics affecting mercury migration processes in the literature.

\section{Materials and methods}

Mineralization degree, cathode-anion composition, as well as mercury content were determined in soil samples at different depths of occurrence. The granulometric and microaggregate composition was determined by sieving (GOST 12536-79), nitrates content was identified by photometric method (GOST 26488-85), the content of carbonates and bicarbonates' ions was evaluated by titration with sulfuric acid solution (GOST 26424-85), chloride ions were determined by argentometric titration method with silver nitrate solution (GOST 26425-85), sulfate ions were identified by weighing method after deposition with barium chloride solution (GOST 26426-85). Additionally, soil filtration coefficients were determined (GOST 25584-90). Mercury concentration was determined by atomic adsorption method with pyrolytic samples decomposition. The analysis was carried out on 22 wells at a depth of $0.5-2$ meters, total of 87 samples were investigated. Statistical data analysis included correlation and regression analysis.

Water samples and bottom sediments of the Irtysh river were taken simultaneously, 40 samples of water and 88 samples of bottom sediments were investigated. Research was carried out up to Tatarka village located $17 \mathrm{~km}$ from the border with the Republic of Kazakhstan. Water sampling was carried out in the most turbulent sections of the river, where more active mixing should take place. Bottom sediments were taken at the shoreline with a depth of $15 \mathrm{~cm}$ into the bottom by scooping.

"Pamyati Azieva" soft spring wheat variety was used as a plant object, its mercury content was determined by the atomic absorption method.

\section{Results and Discussion}

The area under study is a dry steppe with mostly chestnut soils. The valley of the river Irtysh is located at the west side, which is dominated by chernozem floodplain soils.

The concentration of mercury at the study sites did not exceed the normative values (0.1-4 $\mathrm{mg} / \mathrm{kg}$ ). The lowest concentrations of toxic substance were determined near the Irtysh river (0.2-0.5 mg/kg) (Figure 1, 2).
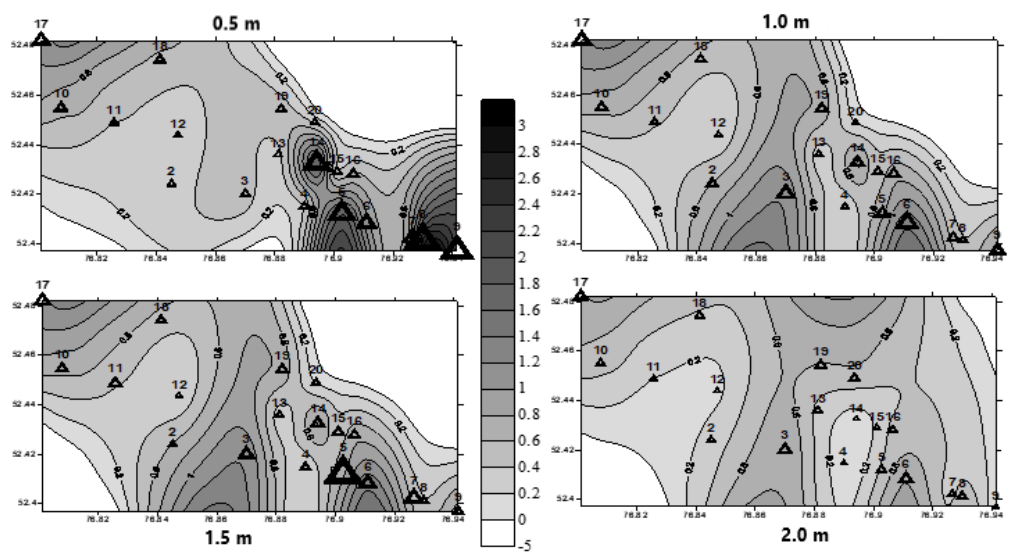

Mercury concentration, $\mathbf{m g} / \mathbf{k g}$

Fig. 1. Mercury distribution in the soil cover of the studied area

Triangle size corresponds to mercury concentration (higher/lower) 


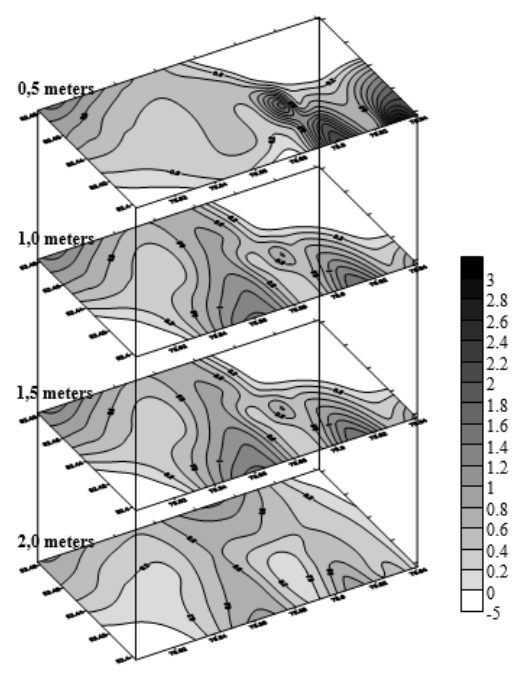

Fig. 2. The nature of the change in mercury concentration with depth

The maximum mercury concentration was observed on the territory of the plant, where the focus of strongly salted and brackish formations of chloride and alkaline composition was found. Further, the pollution aureole spreads to the west, crosses the highway and deviates to the north covering the territory of Pavlodar state farm.

Throughout the observations from 1997 to 2020, despite a general decrease in mercury concentration in dynamics, periods of rise in pollution levels were recorded, which then subsequently decreased. Obviously, this process is associated with periodic rise of the groundwater level, flooding, and water logging.

Despite the relatively low mercury content in the westerly direction, the movement of surface mercury pollution to the right bank side of Irtysh has been traced. Individual spots are fixed in the floodplain aureole circuit, characterized by a high level of contamination, and maintaining stability with depth (Figure 3).

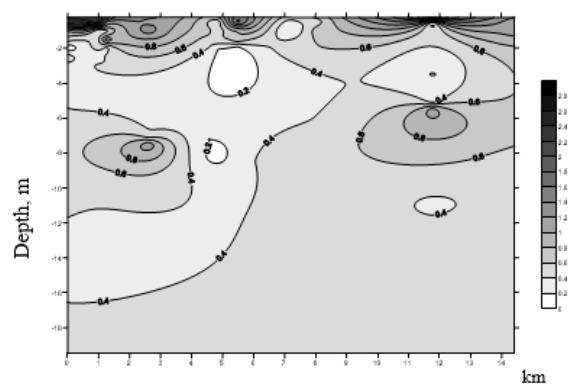

Fig. 3. Mercury distribution on a site near the Irtysh River

Analysis of mercury migration nature depending on the soil type concluded that chernozem soil can bind and retain mercury compounds. It is this humus-rich soil type that was found in the area of the Irtysh floodplain, where the minimum mercury concentrations were recorded. A higher mercury concentration has been found in areas with steppe chestnut soils containing significantly lower amounts of humus. Consequently, these lowhumus soils do not have the ability to securely bind mercury, and therefore it penetrates to depth together with filtering waters. Thus, in soils with low humus content, heavy metals 
are likely to enter groundwater with consequent mercury migration together with it to the Irtysh floodplain.

Soil filtration rates near the river amounted to 18.2 to $35.2 \mathrm{~cm} /$ day. With the distance, the filtration coefficient decreased to $16.8-32.9 \mathrm{~cm} /$ day and amounted to $11.5-14.3 \mathrm{~cm} /$ day in the territory of maximum contamination. This indicates a high rate of mercury migration with groundwater near large water sources if it enters such a site from adjacent areas.

Cation-ion soil analysis revealed predominance of ions $\mathrm{Cl}^{-}, \mathrm{NCO}_{3}^{-}, \mathrm{SO}_{4}^{-2}$ in this territory. The degree of mineralization ranged from 0.73 to $17.1 \mathrm{~g} / \mathrm{dm}^{3}$. Mercury concentration in soils was directly dependent on the degree of their mineralization $(r=0.59$, $\mathrm{p} \leq 0.05$ ). It can be concluded that mercury forms complex compounds by interacting with the mineral component. Such compounds are durable and resistant and contribute to the desorption of movable mercury forms from the surface of soil particles. We conducted a regression analysis and derived the formula describing this dependence: $\mathrm{Y}=0,3994 * 0.161$; the calculated approximation is 0.16 (Figure 4).

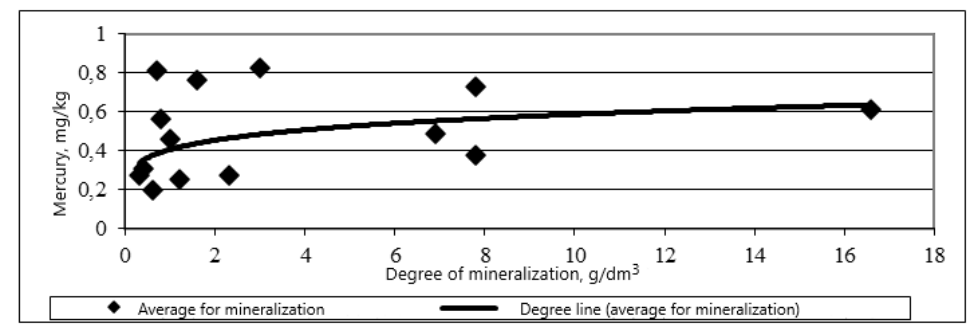

Fig. 4. Ratio of mercury concentration and mineralization level

$\mathrm{HCO}_{3}{ }^{-}$ions, $\mathrm{SO}_{4}{ }^{-2}, \mathrm{Cl}^{-}$were found on sites in the following combinations: $\mathrm{HCO}_{3}{ }^{-} ; \mathrm{SO}_{4}{ }^{-2}$ and $\mathrm{Cl}^{-} ; \mathrm{SO}_{4}^{-2}$ and $\mathrm{Cl}^{-} ; \mathrm{HCO}_{3}^{-}, \mathrm{SO}_{4}^{-2}$ and $\mathrm{Cl}^{-} ; \mathrm{Cl}^{-}$. The statistically reliable linear relationship between the level of mercury accumulation and the content of various ions in soils $\mathrm{r}=0.81 \quad(\mathrm{p} \leq 0.05)$ was revealed (Figure 5). As it is known, mercury is a strong complex former. $\mathrm{HCO}_{3}{ }^{-}$and $\mathrm{Cl}^{-}$ions have the property of forming complex compounds with mercury, so they bind it into soluble compounds. The calculated linear regression equation is as follows: $\mathrm{Y}=0.943 \mathrm{x}+0.1227$, with approximation value $\mathrm{R}_{2}=0.9696$.

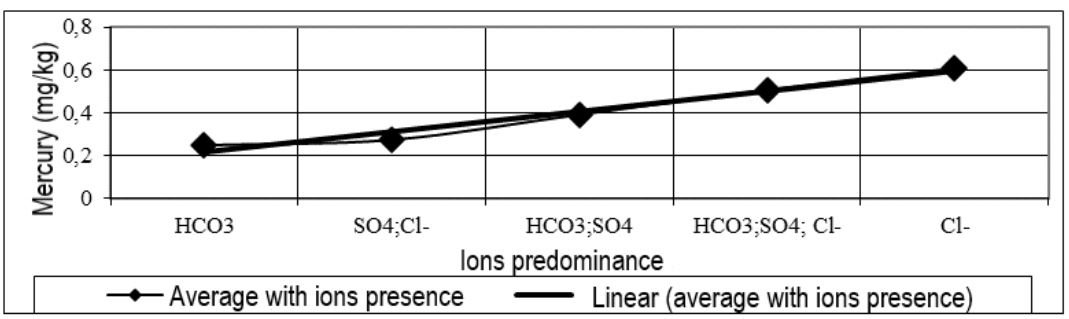

Fig. 5. Mercury concentration in soils depending on their cation-anionic composition

Regression dependence characterizing the dynamics of mercury concentration change in soils of different anionic composition has the form: $\mathrm{Y}=0.0759 \mathrm{x}+0.2906$. Direct dependence of mercury concentration increase on presence of $\mathrm{SO}_{4}{ }^{-2}, \mathrm{HCO}_{3}{ }^{-}$, and $\mathrm{Cl}^{-}$ions in chemical composition of soils with an approximation validity value $\mathrm{R}_{2}=0.8098$ was revealed. 


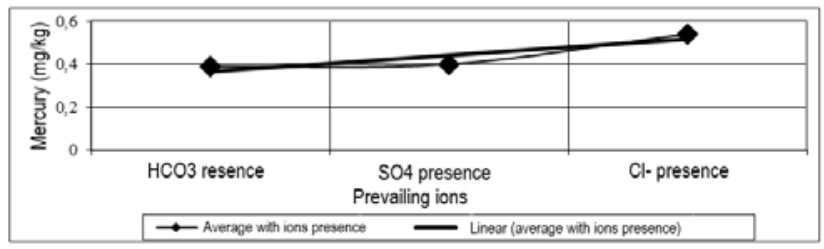

Fig. 6. Influence of major ions on mercury accumulation

The toxic substance accumulation dynamics analysis performed from 2010 to 2018 showed that accumulation is higher- with increased concentration of chlorine ions in the soil cover and lower- compared to years with the predominant content of $\mathrm{HCO}_{3}{ }^{-}$and $\mathrm{SO}_{4}{ }^{-2}$ ions (Figure 7). Chlorine ions contribute to mercury release and form more stable complexes than other ions, contributing to the retention of mercury in soils.

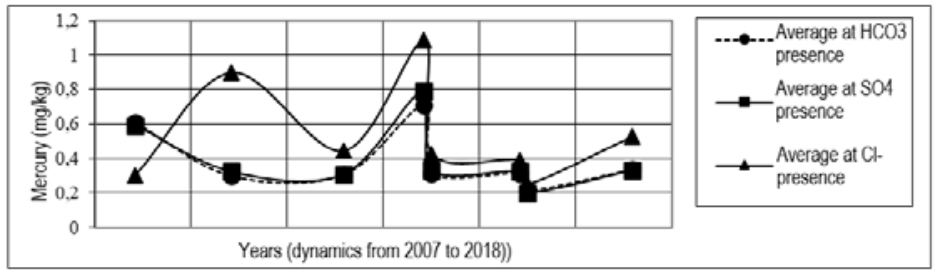

Fig. 7. Mercury accumulation in soils in the presence of various ions

Analysis of the amount of mercury in surface waters and bottom sediments of the Irtysh River found no exceedances of the maximum permissible values. Surface water analysis was carried out along the course of the Irtysh River starting from Maly Atmas village through the city of Omsk and ending below Solyanoe lake. The mercury content of all the ranges was approximately the same at $0.0001-0.0002 \mathrm{mg} / \mathrm{l}$.

Despite the absence of deviation from the norms, the mercury content in bottom sediments differed significantly in different zones $(\mathrm{r}=0.52, \mathrm{p} \leq 0.05)$. In the immediate vicinity of the pollution source, the gross mercury content averaged $0.037 \mathrm{mg} / \mathrm{kg}$, near Beregovoe village, Bolshoy Atmas village, below Solyanoe lake $-0.020 \mathrm{mg} / \mathrm{kg}$, below Cherlak village and near Verkh-Ilinka village $-0.015 \mathrm{mg} / \mathrm{kg}$. The calculated variation coefficient showed the absence of significant variation in the indicator in different years.

Mercury content in wheat tissues growing at the study sites correlated with mercury content in soils: agricultural plants can accumulate mercury in significant quantities. The accumulation factor determined by the ratio of mercury content in wheat tissues to that in soil, amounted to 1.8-2.4. Mercury concentration in plants ranged from 0.0025 to 0.038 depending on the location of growth. Relatively low mercury concentration was found in "Pamyati Azieva" variety wheat tissues on the territory adjacent to the Irtysh floodplain rich in chernozem. During the comparative analysis of mercury accumulation in the stems, leaves and roots of wheat, the predominant accumulation of mercury in the roots- of about $60 \%$ of the total mercury accumulation by all tissues of the plant $(\mathrm{r}=0.52, \mathrm{p} \leq 0.05)$ was found. Similar results were also found in studies of Chinese scientists investigating mercury content in spinach [2].

\section{Conclusion}

There is a clear trend of mercury content decrease in soils with depth. Mercury migrates unevenly to the underlying layers, but it is possible to forecast the level and rate of 
migration depending on the cation-anion composition and the degree of soil mineralization. High soil mineralization contributes to an increase in the amount and rate of mercury penetration into deep soil layers. The average mercury content in soil is higher when chlorine ions are present in it, compared to the presence of sulfate and carbonate ions in soils- irrespective of the intended level of contamination from the source. The linear dependence of mercury concentration growth depending on the presence of sulfate, bicarbonate and chloride ions in soils was also revealed.

Mercury's ability to migrate with groundwater to the nearest water source depends on the soil type. Humus-enriched soils hold mercury more firmly and prevent its migration to plant organisms and groundwater.

On the example of the studied plant object - wheat variety "Pamyati Azieva", it is possible to conclude the easy mercury penetration into agricultural plants and accumulation in them.

\section{References}

1. S. Liua, X. Wang, G. Guo, Z. Yan, Journal of Environmental Management, 277, $111442(2021)$

2. W. Zhao, Y. Cui, X. Sun, H. Wang, X. Teng, Science of The Total Environment, 758, 143883 (2021)

3. P. A. Pérez, H. Hintelmann, G. Lobos, M. A. Bravo, Chemosphere, 237, 124535 (2019)

4. Q. Mao, L. Tang, W. Ji, H. Rennenberg, B. Hu, M. Ma, Ecotoxicology and Environmental Safety, 208, 11605 (2021)

5. P. Pei, T. Sun, Y. Xu, Y. Sun, Chemosphere, 129987 (2021)

6. Y. Wang, T. He, D. Yin, Y. Han, X Zhou, G. Zhang, X. Tian, Ecotoxicology and Environmental Safety, 204, 111121 (2020)

7. J. Xu, J. Zhang, Y. Lv, K.Xu, S. Lu, X. Liu, Y. Yang, Ecotoxicology and Environmental Safety, 195, 110472 (2020)

8. T. Wang, G. Yang, H. Du, P. Guo, T. Sun, S. An, D. Wang, M. Ma, Ecotoxicology and Environmental Safety, 208, 111402 (2021) 